\title{
SAUDAÇÃO A CELSO LAFER, PROFESSOR EMÉRITO
}

\author{
TRIBUTE TO EMERITOUS PROFESSOR CELSO LAFER
}

Fernando Dias Menezes de Almeida*

Celso Lafer iniciou seu discurso de posse como Professor Titular da Faculdade de Direito da Universidade de São Paulo invocando a inserção daquela Casa em seu "léxico-familiar". Neste sentido homenageou a memória de seu pai, A. Jacob Lafer, e do primo de seu pai, Horácio Lafer. (LAFER, 1990, p. 289).

Mas a mesma ideia de família permite afirmar que Celso Lafer passou a integrar, com toda pertinência, o âmbito familiar das gerações que, ao longo de décadas, construíram a tradição de liberdade e democracia que associam o Largo de São Francisco às mais valorosas tendências do constitucionalismo ocidental, fundamentado na garantia dos direitos humanos e na limitação do poder estatal.

Com essa afirmação, não pretendo negar a existência de pensamento antagônico, ou ao menos diverso, nas Arcadas, em distintas épocas. No entanto, a referida tradição de defesa das liberdades e dos direitos fundamentais, com a necessária inserção em um contexto democrático, ao prevalecer, traz inerentes a si os valores do pluralismo e da tolerância, de modo a acolher e incluir a diversidade, com ela dialogando, numa lógica que privilegia o consenso, respeitadas as diferenças.

Celso Lafer não apenas integra esta tradição, como hoje é um de seus maiores expoentes, cumprindo o compromisso que assumiu perante seus pares na Faculdade de Direito, de direcionar suas atividades como Professor Titular à realização da "civilidade do efetivo reconhecimento dos direitos humanos" e seguir a lição de Tocqueville de "amar a liberdade por gosto e a igualdade por instinto e por razão”. (LAFER, 1990, p. 295).

Esta tradição, como visto, é identificada pelos valores de liberdade e democracia que sustenta: este seu sentido funcional. Entretanto, num sentido estrutural para invocar aqui a dicotomia desenvolvida por Norberto Bobbio e sustentada por Celso Lafer (2007) - identifica-se por mesclar, "na sua trama, o Direito, as Letras, a Filosofia e a Política", elementos presentes na formação pessoal de Celso Lafer, bem como "presentes entre os alunos e professores da nossa Casa, desde os seus primórdios", segundo seu próprio depoimento. (LAFER, 1990, p. 292).

Antes de avançar, permitam-me uma breve referência pessoal para explicitar a honra que me dá a Congregação da Faculdade ao indicar-me para em seu nome saudar o

\footnotetext{
* Professor Titular do Departamento de Direito do Estado da Faculdade de Direito da Universidade de São Paulo e Diretor Administrativo da Fundação de Amparo à Pesquisa do Estado de São Paulo.
} 
Professor Emérito Celso Lafer. Ser escolhido pela Congregação para semelhante missão já seria altamente honroso; tanto mais em se tratando de dirigir-me ao nosso homenageado.

Fui aluno - no sentido formal, na sala de aula - do Professor Celso Lafer por muito pouco tempo: algumas semanas no início do curso de Filosofia do Direito, em meu quarto ano da graduação, em 1992. O suficiente para trazer comigo a admiração por suas virtudes didáticas e por sua clareza de raciocínio ao transmitir de modo acessível conteúdos de grande complexidade. Logo o Professor interrompeu as aulas para aquela turma, atendendo a uma missão de evidente interesse nacional, assumindo o Ministério das Relações Exteriores.

Posso dizer, no entanto, que até hoje sou seu aluno, como todos que permanentemente aprendemos com suas obras. Porém, tive ainda o privilégio de com ele conviver ao longo de 8 anos, como seu assessor na Presidência da Fundação de Amparo à Pesquisa do Estado de São Paulo (FAPESP), ocasião em que pude testemunhar, entre tantas outras realizações em benefício dessa importantíssima instituição paulista, como o Professor Celso Lafer conduziu a FAPESP a inédito e admirável patamar de inserção internacional.

Citar a íntegra do currículo de Celso Lafer é algo incompatível com o tempo que, no limite da razoabilidade, deve durar esta sessão. Permitam-me referir - com o risco de incidir na redundância de proclamar o notório - que Celso Lafer, professor emérito da Universidade de São Paulo e de seu Instituto de Relações Internacionais foi, até a sua aposentadoria em 2011, professor titular do Departamento de Filosofia e Teoria Geral do Direito da Faculdade de Direito da USP, na qual estudou (1960-1964) e na qual começou a lecionar, em 1971, Direito Internacional e Filosofia do Direito.

Obteve o seu MA (1967) e o seu PhD (1970) em Ciência Política na Universidade Cornell (EUA); a livre-docência em Direito Internacional Público na Faculdade de Direito da USP em 1977 e, na mesma Faculdade, a titularidade em Filosofia do Direito em 1988.

Na Faculdade de Direito da USP foi Chefe do Departamento de Filosofia e Teoria Geral do Direito (1993-1995; 2003-2005; 2009-2011). Integrou a Área de Concentração de Direitos Humanos da qual foi Coordenador (2006-2007) e Vicecoordenador (2007-2011). Representou a Congregação da Faculdade de Direito no Conselho Universitário da USP (1990-1992). Foi membro titular do Conselho Deliberativo do Instituto de Relações Internacionais (IRI) da USP (2005-2011). Integra o Conselho Deliberativo do Instituto de Estudos Avançados da USP.

De 2007 a 2015, presidiu a FAPESP - Fundação de Amparo à Pesquisa do Estado de São Paulo.

Foi Ministro de Estado das Relações Exteriores em 1992 e, nesta condição, Vice-Presidente ex officio da Conferência da ONU sobre Meio Ambiente e 
Desenvolvimento, a Rio-92. Na sua segunda gestão no Itamaraty (2001-2002) chefiou a delegação brasileira à Conferência Ministerial da Organização Mundial do Comércio (OMC) em Doha, que deu início à Rodada de Doha. Em 1999 foi Ministro de Estado do Desenvolvimento, Indústria e Comércio. De 1995 a 1998 foi Embaixador, Chefe da Missão Permanente do Brasil junto às Nações Unidas e à OMC em Genebra. Em 1996 foi o Presidente do Órgão de Solução de Controvérsias da OMC e, em 1997, foi Presidente do Conselho Geral da OMC. Presidiu na OMC, relevantes Panels. É Membro da Corte Permanente de Arbitragem Internacional de Haia desde 2002.

Seu currículo indica ainda diversas atividades culturais e empresariais. Preside o Conselho do Museu Lasar Segall e é o Presidente da Fundação Cultural Ema G. Klabin. Integra o Conselho de Administração de Klabin. Foi Vice-presidente do Conselho de Administração da Associação Pinacoteca Arte e Cultura. Foi membro do Conselho de Administração da Fundação Orquestra Sinfônica do Estado de São Paulo (Fundação OSESP) e atualmente integra o seu Conselho de Orientação. É Vice-Presidente do Conselho Deliberativo da Unibes e Presidente do Conselho Consultivo do Hospital Israelita Albert Einstein.

Doutor honoris causa da Universidade de Buenos Aires (2001), da Universidade Nacional de Córdoba, Argentina (2002), da Universidade de Tres de Febrero-UNTREF, Argentina (2011), da Universitè Jean Moulin Lyon 3, França (2012), da Universidade de Haifa (2014), da University of Birmingham (2014) e Honorary Fellow da Universidade Hebraica de Jerusalém (2006). Em 2006 foi titular da cátedra "Países e Culturas do Sul" do Centro John W. Kluge da Biblioteca do Congresso dos EUA.

Publicou inúmeros livros e artigos científicos, os quais naturalmente o tempo de que dispomos não me permite enunciar. Por sua produção, além do notório reconhecimento científico, também recebeu prêmios como o Prêmio Jabuti em 1989 pelo seu livro de 1988 A Reconstrução dos Direitos Humanos - um diálogo com o pensamento de Hannah Arendt e Prêmio da APCA de 2013 na área Biografia/Memória, pelo livro Norberto Bobbio: Trajetória e Obra.

Peço desculpas ainda por não mencionar especificamente todas as demais homenagens que já recebeu, lembrando apenas o prêmio Moinho Santista da Fundação Bunge na área de Relações Internacionais e o Prêmio Professor Emérito - Troféu Guerreiro da Educação Ruy Mesquita, concedido anualmente pelo Centro de Integração EmpresaEscola (CIEE).

É membro titular da Academia Brasileira de Ciências, eleito em 2004. Em 2006, foi eleito o quinto ocupante da cadeira 14 da Academia Brasileira de Letras. Membro efetivo da Academia Paulista de Letras, eleito em 2014. Membro também do Instituto dos Advogados do Brasil e do Instituto dos Advogados de São Paulo. 
Os temas abordados por Celso Lafer em sua carreira jurídica e políticoadministrativa são inúmeros. Valho-me aqui de suas próprias palavras em um de seus artigos mensais no jornal $O$ Estado de São Paulo, ao relatar sua obra recentemente publicada em três volumes - Direitos Humanos, Direito Internacional, Filosofia e Teoria Geral do Direito -, sob o título geral Um Percurso no Direito no Século XXI, e que reúne alguns de seus trabalhos escritos neste século, numa significativa síntese de seu percurso intelectual: (LAFER, 2015).

Verifico que as linhas da minha reflexão acabaram antecipando tendências e estão em sintonia com a importância que vem sendo atribuída à tutela dos direitos humanos, tanto no plano interno, à luz da Constituição de 1988, quanto no plano externo, por obra da política do Direito traçada pela Declaração Universal de 1948. Também estão em sintonia com a crescente relevância da agenda do Direito Internacional Econômico, que, por obra da interdependência, vem ampliando o repertório e o escopo de normas de mútua colaboração, reguladoras da transferência internacional de recursos. Daí a importância tanto do regionalismo de múltiplos processos do Direito de Integração quanto do alcance de multilateralismo comercial, de que a OMC e o seu Sistema de Solução de Controvérsias são uma expressão e em conjunto são parte do fenômeno mais amplo da globalização do Direito.

As janelas do espírito se abrem por dentro, como dizia o professor Miguel Reale, e foram suas aulas e as do professor Goffredo Telles Jr. que abriram as janelas do meu interesse pela Filosofia do Direito. A Filosofia do Direito coloca o problema epistemológico de um apropriado equilíbrio na determinação do alcance e extensão dos seus campos de investigação. Enquanto filosofia, não pode deixar de lado preocupações teóricas, mas enquanto Direito diz respeito à práxis. É por essa razão que a Filosofia do Direito, no meu entender, é um campo do conhecimento construído e elaborado por juristas com interesses filosóficos voltado para um parar para pensar problemas que não encontram adequado encaminhamento no âmbito estrito do Direito Positivo. [...]

A Filosofia do Direito comporta também, como diria Bobbio, uma funzione civile voltada para a reflexão sobre os grandes problemas do Estado e do Direito. O Direito não é só experiência, mas não pode ser entendido sem ela. Foram os eventos da experiência vivida do regime autoritário de 1964 que me levaram a refletir sobre os méritos do governo das leis como superior ao dos homens e na especificidade da relação governantes/governados a indispensabilidade para a qualidade da convivência coletiva da tutela dos direitos humanos. Os direitos humanos consagram a democrática 
perspectiva ex parte populi representativa da passagem do dever dos súditos para os direitos dos seres humanos e são uma expressão do tema arendtiano do direito a ter direitos.

Para prosseguir nesta saudação, pareceu-me pertinente destacar um tema das lições de Celso Lafer, presente tanto em sua obra teórica como em suas ações enquanto homem público, que permite evidenciar o modo muito especial como construiu sua trajetória e, ao mesmo tempo, ilustrar algumas perspectivas dos valores fundamentais de seu pensamento, defensor dos direitos humanos, da democracia, do pluralismo e da tolerância. Trata-se do tema da relação, da conciliação, entre o direito e a política.

Ao fazê-lo, pretendo ao mesmo tempo deixar transparecer uma nota característica da obra de Celso Lafer, como é peculiar à obra dos grandes pensadores: a explicitação do reconhecimento e do respeito à herança intelectual de seus mestres.

Neste sentido, sobre o tema da relação entre direito e política, é claro o diálogo de seu pensamento com o de Miguel Reale. Em suas próprias palavras: “como Reale, estou igualmente convencido, depois de alguns anos de estudo e ensino de Direito Internacional Público, de que: 'Estão destinados a insucesso todas as doutrinas que procuram eliminar do Direito o conceito de 'poder', ou então tentam reduzir o poder a uma 'categoria jurídica pura"”, (LAFER, 1981, p. 206).

Momento crucial da relação entre direito e poder é o do ato de decisão presente na criação normativa. Segundo Celso Lafer, "não se cria uma norma jurídica sem a voluntas de um ato decisório do poder com validade para outrem. Esta exprime assim a kantiana heteronomia do processo de realizabilidade do Direito na vida social". (LAFER, 2000, p. 98).

No entanto, acompanhando Reale, Celso Lafer reconhece que o ato decisório do poder não é incondicionado - como seria "à maneira do decisionismo radical de Carl Schmitt, que afirma a plenitudo potestatis do monopólio da decisão de soberania” -, mas sim "condicionado pela ratio de um quadro de possibilidades normativas, derivado da interação entre Fato e Valor” (LAFER, 2000, p. 98); enfim: “O leque de proposições normativas em relação ao qual incide a voluntas decisória do poder numa dada conjuntura política e no seu momento histórico não é ilimitado. É condicionado pela ratio de um espectro de coeficiente de estimativas, organizada por uma tábua de valores". (LAFER, 2000, p. 99).

Avançando em suas ponderações, Celso Lafer mostra ainda que esta ratio condicionante ao ato decisório do poder, por sua vez, é condicionada pela legitimidade, (LAFER, 2000, p. 104) sendo - como pondera em outra passagem - "difícil discutir a justiça das normas, sem examinar a legitimidade do poder, que representa uma proposta de organização da vida em sociedade". (LAFER, 1990, p. 294). 
Apreendendo com precisão o problema fundamental a ser resolvido pela democracia liberal hoje, Celso Lafer mostra que "no Estado contemporâneo, a gênese das normas se prende a um complexo processo decisório, por meio do qual as instituições políticas, no exercício de uma função hierárquica de gestão da sociedade, convertem preferências e aspirações de grupos ou indivíduos em decisões públicas"; e, para que tal processo seja democrático, há que ser presidido pela "importância do reconhecimento do Outro", do que resulta ser a "Democracia uma tentativa de organizar o poder numa sociedade, de tal forma que se dê essa mediação bem sucedida entre Estado e Sociedade Civil, em cujo vértice se encontra o tema da legitimidade”. (LAFER, 1978, p. 10-11).

$\mathrm{E}$ a dificuldade inerente à democracia reside no fato de que o "acatamento às normas assim criadas envolve uma mediação bem-sucedida das instituições políticas na obtenção do consenso dos governados", mediação esta que, no entanto, se torna complexa, "seja porque não pode apoiar-se apenas na força do monopólio da coerção organizada, seja porque a política não é o campo da razão pura, onde as soluções são evidências que se impõem a todos, incontrastavelmente, como one best way". ${ }^{1}$ (LAFER, 1978, p. 10-11).

As constatações acima referidas - sobre as relações, no regime democrático, entre direito e poder, entre instituições jurídicas e políticas ante a decisão presente na criação normativa, orientadas pelas noções de legitimidade e consenso -, Celso Lafer não as edificou somente a partir de seu pensamento abstrato; também buscou lastreá-las concretamente, por exemplo, ao estudar o processo de planejamento e sistema político no Brasil, consubstanciado no Programa de Metas produzido pelo Presidente Juscelino Kubitschek (sua tese de doutorado em ciência política, obtido na Cornell).

Com efeito, após aprofundada análise, reconhecendo que Kubitschek soube bem "interpretar as características da representação e da participação políticas no Brasil”, Celso Lafer conclui que, enquanto instrumento do processo decisório, o Programa de Metas serviu, durante a campanha eleitoral, "como garantia e promessa de atender às necessidades das massas e aos interesses das elites", e, já no exercício do poder, permitiu ao Presidente dele se valer como "um conjunto de políticas sobre as quais o consenso podia ser aferido com probabilidades reais de acerto" (LAFER, 2002, p. 49) - o que leva a decisões administrativas satisfatórias. ${ }^{2}$

E mais, Celso Lafer não apenas constatou tais relações na conduta de outros agentes governamentais, como efetivamente as praticou: “a minha experiência” - são suas

Em outra elucidativa passagem: "A falácia do caminho de mão única provém do fato de que a política requer um modo de pensar no plural, que não é o da evidência racional do eu consigo mesmo, mas sim o do diálogo com os outros na intersubjetividade que caracteriza a política e o Direito". (LAFER, 1980b, p. 29).

2 Característica própria, aliás, das decisões administrativas: "a decisão administrativa nunca é ótima, mas normalmente é apenas satisfatória: é uma decisão que satisfaz, e não que otimiza, dentro dos limites reais da racionalidade". (LAFER, 2002, p. 50). 
palavras - "com propostas normativas e a sua conversão em normas jurídicas, seja no plano internacional, como Ministro das Relações Exteriores, em 1992, e Embaixador em Genebra, na OMC e na ONU, de 1995 a 1998, seja no plano interno, como Ministro do Desenvolvimento, Indústria e Comércio, em 1999, é confirmatória e se ajusta à avaliação que fiz, inspirado por Miguel Reale, do papel da legitimidade na correlação entre Direito e poder". (LAFER, 2000, p. 105).

Se, por um lado, como acima se ressaltou, o poder é elemento necessário para a compreensão do direito, sobretudo no tocante à decisão presente na criação normativa, por outro lado, ainda na perspectiva das democracias liberais, é função do direito "domesticar" o poder.

A atuação por um direito que domestique o poder é marcante, mostra-o Celso Lafer, na vida e na obra de Norberto Bobbio (LAFER, 1998, p. 103) - outro mestre que Celso Lafer reverencia e, com ele compartilhando valores e ideias, faz do diálogo nascerem ideias próprias, que reforçam a causa por que militam. ${ }^{3}$

Esta visão de um “diritto al di sopra del potere”, (LAFER, 1998, p. 103) marca, na perspectiva de Bobbio, "a transformação do Estado absolutista e arbitrário num Estado de Direito" e pode ser medida pela "extensão do mecanismo de sanção, da base para o vértice da pirâmide jurídica, isto é, dos cidadãos para os governantes".

Sim, pois mostra Celso Lafer que "este processo, que assinala a passagem da irresponsabilidade para a responsabilidade jurídica de cargos, órgãos e funções e a substituição da força arbitrária por poderes juridicamente controlados e disciplinados, é uma das conquistas da técnica do Estado de Direito e da reflexão liberal". (LAFER, 1980a, p. 11).

Com efeito, o estado de direito, grande criação da tradição liberal do mundo ocidental, fundamenta-se na ideia da legalidade, que, ao mesmo tempo, legitima o poder.

A legalidade, no estado de direito, de rigor, deve ser vista, como ensina Celso Lafer dialogando com Bobbio, como "qualidade do exercício do poder, que

\footnotetext{
Eis oportuna passagem de Celso Lafer sobre a militância política de Bobbio: "Esta postura de Bobbio, na sua crítica ético-política, quanto ao tema da legitimidade e da legalidade, resulta, creio eu, da firmeza de suas conviç̧ões liberais e da generosidade de sua militância socialista. Raymond Aron tem razão quando afirma que os liberais da linhagem de Tocqueville, entre os quais se inclui Bobbio, participam sem receio da empresa prometeica do futuro, esforçando-se para agir segundo as lições, por mais incertas que sejam, da experiência histórica, preferindo conformar-se com as verdades parciais que recolhem do que valerse de falsas visões totais. Já os socialistas democráticos, como Bobbio, de extensos conhecimentos de filosofia, não fazem parte daqueles que dizem: 'É preciso tudo destruir para, a seguir, recomeçar da estaca zero'. Como afirma outra grande figura contemporânea da esquerda democrática, Pierre Mendès-France, na conclusão de seu livro La Vérité Guidait leurs Pas: 'On ne répart pas de zéro - ou alors on impose des cruautés et des convulsions que nous avons le devoir d'épargner aux plus faibles et aux nouvelles générations. Et on perds du temps. Je suis impatient”'. (LAFER, 1980a, p. 19).
} 
interessa antes aos governados do que aos governantes, uma vez que impede a tyrannia quoad exercitium". (LAFER, 1980a, p. 11).

Neste sentido, o problema da legalidade ex parte populi identifica-se na "determinação e verificação", por meio do direito, de quatro aspectos: a) quando e em que condições o poder coativo da coletividade pode e deve ser exercido; b) quem pode exercer esse poder em nome da coletividade; c) como, ou seja, quais os procedimentos pautam o exercício desse poder; e d) quanto de força devem e podem dispor em tal função. (LAFER, 1980a, p. 11).

Por outras palavras, o estado de direito liberal pode ter sua essência compreendida pelo sentido finalístico de eliminação do arbítrio do governante, com a substituição de sua vontade subjetiva, pela vontade objetiva contida na lei.

As breves reflexões dos tópicos anteriores tiveram por objetivo mostrar que não se pode compreender o direito, enquanto fenômeno social, sem se aceitar que a noção de poder com ele se relaciona.

O fenômeno jurídico, finalisticamente voltado à garantia da liberdade, é, portanto, inseparável do fenômeno político.

Celso Lafer - neste passo elaborando seu pensamento a partir de Hannah Arendt - demonstra que política e liberdade "são coincidentes, porém só se articulam quando existe mundo público". (LAFER, 1972, p. 21). Sim, pois o "campo da Política é o diálogo no plural que surge no espaço da palavra e da ação - o mundo público - cuja existência permite o aparecimento da liberdade. De fato, a consciência da presença ou da ausência da liberdade ocorre na interação com os outros e não no diálogo metafísico do eu consigo mesmo". (LAFER, 1972, p. 21).

Explique-se melhor. Para Hannah Arendt - é Celso Lafer que o ensina - o campo da política não é o da razão pura, nem o da razão prática, pois em ambos os casos "os modos de asserção do conhecimento têm, para usar uma distinção de Tércio Sampaio Ferraz Jr., uma estrutura discursiva monológica”. (LAFER, 1972, p. 17).

A verdade matemática e a verdade científica seguem uma lógica de justificação por um elemento intrínseco que as torna indiscutíveis. Mesmo as verdades filosófica e moral seguem uma estrutura monológica, esta voltada ao sujeito que as formula, na sua singularidade, respectivamente resultando no princípio lógico da nãocontradição e no princípio ético da concordância com a própria consciência. (LAFER, 1972, p. 17).

Entretanto, a política "como aponta Hannah Arendt, se insere num outro contexto e o seu campo é o do pensamento no plural" - que implica a capacidade "de pensar no lugar e na posição dos outros em vez de estar de acordo consigo mesmo". (LAFER, 1972, p. 17-18). 
Não se trata de abrir mão do próprio pensamento e das próprias convicções. Mas trata-se de um juízo decorrente da mentalidade alargada - na expressão kantiana empregada por Celso Lafer -, que implica uma "concordância potencial com os outros". (LAFER, 1972, p. 18).

Grife-se o "potencial": é a abertura para o respeito pelo outro, sem anulação de si mesmo; é a realização do pluralismo, sem o qual não há democracia e perece a liberdade.

"Da mentalidade alargada" - é ainda Celso Lafer que ensina - "provém o consenso, que para Hannah Arendt parte do reconhecimento que o homem não pode agir sozinho, isoladamente, pois os homens, se querem conseguir algo no mundo, precisam atuar conjuntamente. É do nós do agir conjunto que nasce o poder, entendido como um recurso gerado pela capacidade dos membros de uma comunidade política de concordarem com um curso comum de ação". (LAFER, 1980a, p. 30).

Deste modo, está-se a buscar, na produção democrática do direito, não um juízo com validade universal, mas um acordo, com validade específica, delimitada pelo conjunto das pessoas que tomam parte no diálogo que leva ao acordo. Um acordo resultante na legalidade.

O constitucionalismo liberal, edificando o respectivo modelo de estado de direito lutou para substituir o governo de homens pelo governo das leis.

Todavia, certas visões da prática jurídica, ao cada vez mais buscarem afastar a política do direito, conscientemente ou não, conduzem o estado à armadilha de um novo modo, insidioso, de governo de homens, que poderíamos dizer o governo de homens das leis.

Estas visões partem da ideia (no mais das vezes, implícita) de que o direito, especialmente a constituição, implica um conjunto de dogmas a ser conhecido e realizado. Ignora-se, ou quer-se ignorar, que todo ato jurídico de concretização da norma constitucional e das leis - a norma individual consistente num ato administrativo, ou num ato jurídico privado, ou mesmo num ato jurisdicional - decorre de um ato de vontade, de uma decisão, e não de um ato de puro conhecimento.

Pretende-se, pois, que o melhor processo para a realização do direito seja o recurso àqueles que tecnicamente são aptos a manejar o direito - os homens das leis -, não estando envolvidos, ao menos explicita ou conscientemente, no processo político.

Expressão mais clara do governo dos homens das leis é a postura extremada dos tribunais e de órgãos legitimados a movimentá-los, conhecida como ativismo judicial.

A propósito, Celso Lafer alerta que o "desdobramento e as conseqüências do ativismo judicial [...] suscita a preocupação com os limites objetivos do processo hermenêutico", preocupação "voltada para conter os riscos de a interpretação extrapolar a desejável congruência normativa de uma Constituição, como expressão axiológica do 
mérito do 'governo das leis' e das inconveniências do 'governo dos homens', inclusive o dos magistrados". (LAFER, 2010, p. 12).

Em artigo publicado no mês passado, portanto, com olhos para a realidade que estamos vivendo hoje em nosso País, Celso Lafer volta ao ponto para afirmar: (LAFER, 2018).

Valho-me da sugestividade da distinção entre risco e
incerteza - [logo antes o texto esclarecera, com base em
Frank Knight, que "o que caracteriza o risco é a possibilidade
de ser estimado e calculado, com alguma orientação de
certeza. Em contraste, o que caracteriza a incerteza é a
impossibilidade da estimativa e do cálculo."] - para apontar
que ela esclarece uma importante dimensão da discussão,
ora em curso no Brasil, em torno do Estado de direito, da
dinâmica da divisão dos Poderes, do papel da magistratura,
do Ministério Público e da Polícia Federal. Com efeito, um
dos ingredientes fundamentais da vida do direito hoje no País
é a incerteza jurídica. Essa incerteza vem minando um dos
valores de um ordenamento democrático, que é a segurança
das expectativas, descortinadora da calculabilidade das
consequências das nossas próprias ações. A incerteza
jurídica vem traduzindo na sua dinâmica atual uma gradual
substituição do governo das leis pelo imponderável do
governo dos homens - por mais bem-intencionadas que
sejam suas condutas, inclusive o meritório combate ao
cupim da corrupção.

Ora, a história da edificação do estado de direito e da superação do absolutismo - o que também vale quanto às demais formas de autocracias dos tempos atuais - faz ver os riscos da pretensa separação de direito e política, seja ao se desprezar o sentido político da ação da administração pública de concreção do direito, seja ao se desprezar o sentido político das leis a serem judicialmente aplicadas.

Como mostra Celso Lafer, "o Direito e o poder existem no campo da intersubjetividade de um mundo em comum. ${ }^{4}$ Por esse motivo, são fenômenos que não podem ser captados, no seu perfil próprio, pelo homo theoreticus da reflexão de Spranger, que vive no mundo abstrato das leis da objetividade”. (LAFER, 1981, p. 220-221).

Particularmente aqueles que enxergam o direito pelo viés do direito administrativo - em especial nos países que sofreram influência da matriz francesa, como

$4 \quad$ Em outra obra Celso Lafer enfatiza o sentido intersubjetivo do Poder: "O poder surge quando os homens se reúnem num espaço, sendo a convivência humana o único fator material para a sua geração. Todo aquele que se isola, afirma Hannah Arendt, renuncia ao poder por maior que seja a sua força e por mais válidas que sejam as suas razões. Por isso o poder - ao contrário da violência - é inerente a qualquer comunidade política, que busca manter de maneira viva e permanente a convivência entre os homens". (LAFER, 2006, p. 206). 
é o caso do Brasil - deveriam mostrar-se familiarizados com esta convivência de direito e política.

Este direito administrativo à francesa nasceu e consolidou-se, sobretudo, por obra de um órgão que reúne, inseparavelmente, uma dimensão política e uma dimensão técnico-jurídica: o Conseil d'État. E que, com esta configuração, posicionou-se, reiteradamente ao longo de sua história, como um guardião da legalidade e da liberdade e como um agente de resistência ao abuso do poder dos governantes.

Aliás, Celso Lafer também lembra que a legalidade é garantia que se opõe também ao juiz, de modo que do processo judicial resulte a vontade (objetiva) da lei e não a vontade (subjetiva) do juiz, realizando-se, assim, a liberdade. (LAFER, 2006, p. 221). De fato, a criação normativa pelo juiz também envolve decisão, enquanto ato de vontade; e não difere da decisão administrativa enquanto ato de poder "domesticado" pelo direito.

Mais uma vez citando sua reflexão sobre o tema mais recentemente publicada: (LAFER, 2018).

O Direito, na sua aplicação, não é um dado que comporte apenas uma interpretação. É um construído pela experiência jurídica, mas essa construção não é a de um 'direito livre' que se revela, com autonomia, pelas estruturas argumentativas no processo decisório conduzido no Judiciário. Existem parâmetros para a latitude e o escopo da interpretação. São os provenientes do Direito posto e positivado, a lei, da qual provém a dogmática jurídica. Sua função no processo decisório da aplicação do Direito, como explica Tercio Sampaio Ferraz Jr., é a de impor o princípio da inegabilidade dos pontos de partida das séries argumentativas, inerentes à experiência jurídica. É dessa maneira que os parâmetros dogmáticos da interpretação - a inegabilidade dos pontos de partida estipulados na lei - exercem uma função de contenção da incerteza jurídica e da incerteza jurisdicional, que é uma das suas consequências. Tornam viável avaliar e estimar as condições do juridicamente possível. Ensejam o controle da consistência e da coerência da jurisprudência, e não custa lembrar, com Bobbio, que a coerência é uma virtude jurídica.

Enfim, a conciliação do direito com a política, fundamental para a existência de uma sociedade democrática e defensora da liberdade, é algo não apenas presente na palavra, como também na ação de Celso Lafer, que neste sentido, é exemplo da prática da virtude política, a qual, em sua própria expressão, lembrando Montesquieu, consiste no "amor às leis e à pátria, o que exige a preferência contínua pelo interesse público". (LAFER, 2001, p. 85). 


\section{Referências}

LAFER, Celso. A legitimidade na correlação direito e poder: uma leitura do tema inspirada no tridimensionalismo jurídico de Miguel Reale. In: ZILLES, Urbano (Coord.). Miguel Reale: estudos em homenagem a seus 90 anos. Porto Alegre: EDIPUCRS, 2000.

. A reconstrução dos direitos humanos: um diálogo com o pensamento de Hannah Arendt. São Paulo: Companhia das Letras, 2006.

. Apresentação à edição brasileira. In: BOBBIO, Norberto. Da estrutura à função: novos estudos de teoria do direito. Tradução de Daniela Beccaccia Versiani. Barueri, SP: Manole, 2007. p. LII-LVII.

. Bobbio domestica o poder por meio do direito. Revista Jurídica, Campinas, v. 14, p. 97$103,1998$.

- Direito e poder na reflexão de Miguel Reale. Revista da Faculdade de Direito da Universidade de São Paulo, São Paulo, v. 76. p. 203-221, jan./dez. 1981.

. Discurso de posse como professor titular da Faculdade de Direito da Universidade de São Paulo em 7 de agosto de 1989. Revista da Faculdade de Direito da Universidade de São Paulo, São Paulo, v. 84/85, p. 289-295, jan./dez. 1990.

. Ética e política: uma reflexão sobre o percurso de André Franco Montoro. In: POZZOLI, Lafayette; SOUZA, Carlos Aurélio Mota de (Org.). Ensaios em homenagem a Franco Montoro: humanista e político. São Paulo: Fundação Konrad Adenauer, 2001.

. Insegurança jurídica. O Estado de São Paulo, São Paulo, p. 2, 18 mar. 2018.

. Introdução. Da dignidade da política: sobre Hannah Arendt. In: ARENDT, Hannah. Entre o passado e o futuro. Tradução Mauro W. Barbosa de Almeida. São Paulo: Perspectiva, 1972.

. JK e o programa de metas, 1956-1961: processo de planejamento e sistema político no Brasil. Rio de Janeiro: FGV, 2002.

. O moderno e o antigo conceito de liberdade. In: LAFER, Celso. Ensaios sobre a liberdade. São Paulo: Perspectiva, 1980b. p. 11-48.

. Prefácio. In: RAMOS, Elival da Silva. Ativismo judicial: parâmetros dogmáticos. São Paulo: Saraiva, 2010.

. Prefácio. In: FARIA, José Eduardo. Poder e legitimidade: uma introdução à política do direito. São Paulo: Perspectiva, 1978.

. Prefácio. In: BOBBIO, Norberto. A teoria das formas de governo na história do pensamento político. Trad. Sérgio Bath. Brasília: Universidade de Brasília, 1980a.

. Reflexões de um professor. O Estado de São Paulo, São Paulo, p. 2, 15 nov. 2015. 